\title{
Uso do clorofilômetro no manejo da adubação nitrogenada para milho em sucessão a pastagem de Brachiaria decumbens
}

\author{
Use of chlorophyll meter in nitrogen fertilizing management to corn after Brachiaria \\ decumbens pasture
}

\section{Leandro José Grava de Godoy ${ }^{* I}$ Lauter Silva Souto ${ }^{\mathrm{I}}$ Dirceu Maximino Fernandes ${ }^{\mathrm{I}}$ Roberto Lyra Villas Bôas ${ }^{\mathrm{I}}$}

\section{RESUMO}

A resposta do milho à adubação nitrogenada em cultivo após pastagem depende da espécie, da quantidade de palha, da relação $C: N$, da população microbiana, das condições climáticas e de outros fatores. O objetivo desta pesquisa foi avaliar a utilização da intensidade da cor verde da folha (ICV), medida pelo clorofilômetro, como indicativo para o manejo da adubação nitrogenada em cobertura, na cultura do milho, em sucessão a pastagem de Brachiaria decumbens Stapf. O experimento foi conduzido em casa de vegetação, em vasos com 29 litros de um Latossolo Vermelho distrófico, com três plantas por vaso. Foi utilizado o delineamento de blocos ao acaso, em esquema fatorial $4 \times 4$, com cinco repetições, constituído por quatro níveis de nitrogênio $\left(0,50,100\right.$ e $\left.150 \mathrm{mg} \mathrm{dm}^{-3}\right)$ e quatro de níveis de palhada de $\boldsymbol{B}$. decumbens $\left(0,5,10\right.$ e $\left.15 \mathrm{Mg} \mathrm{ha}^{-1}\right)$, aplicados em cobertura. As doses de $N$ foram parceladas em três épocas: a)1/3 na semeadura; b)1/3 no estádio de 4-5 folhas e c)1/3 no estádio de 7-8 folhas. As determinações da ICV da folha foram efetuadas um dia antes e uma semana após a adubação nitrogenada em cobertura. As quantidades de fitomassa seca de braquiária influenciaram a ICV da folha somente no estádio de 7-8 folhas. A manutenção de maiores ICV da folha do estádio de 4-5 (46,6 unidades SPAD) até o estádio de 8-9 folhas (53,0 unidades SPAD) possibilitou o maior acúmulo da fitomassa seca na parte aérea do milho. O monitoramento da ICV da folha pode auxiliar na avaliação da disponibilidade de $\mathrm{N}$ para a planta do milho durante o ciclo.

Palavras-chave: Zea mays L., SPAD, clorofila e nitrogênio.

\section{ABSTRACT}

The corn response to the nitrogen fertilizing cultivated after pasture depends on of the species, straw amount, $C$ : $N$ rate, microbial population, climatic conditions and other factors. The study was aimed at evaluating the use of the green color intensity of the leaf (GCI), measured by the chlorophyll meter, as indicative for nitrogen fertilizing management sidedress in the corn crop, after B. decumbens Stapf pasture. The experiment was carried out in greenhouse conditions, in pots with 29 liters of a Red Latosol (Oxisol), with three corn plants per pot. The randomized blocks design was used, in $4 \times 4$ factorial arrangement, with five replications, constituted by four nitrogen rates $\left(0,50,100\right.$ and $150 \mathrm{mg} \mathrm{dm}^{-3}$ of soil) and four levels of B. decumbens straw (0,5, 10 and $\left.15 \mathrm{Mg} \mathrm{ha}^{-1}\right)$, applied in sidedressing. The $N$ doses were splitting in three times: a) $1 /$ 3 in the seeding; b) 1/3 in the 4-5 leaves stage and c) 1/3 in the 7-8 leaves stage. The determinations of GCI of the leaf were made one day before and one week after the sidedress nitrogen fertilizing. The levels of $\boldsymbol{B}$. decumbens straw only influenced GCI in the seven-eight leaves stage. The maintenance of larger GCI of the four-five leaves stage (46.6) to the eight-nine leaves (53.0) made possible the largest accumulation of the corn shoot dry matter. The monitoring of GCI can help in the evaluation of the $N$ available for the corn during season.

Key words: Zea mays L., SPAD, chlorophyll and nitrogen.

\section{INTRODUÇÃO}

A área de pastagem no Brasil é de, aproximadamente, 171 milhões de hectares, abrangendo tanto as vegetações nativas quanto as cultivadas (MEIRELLES, 1999). Somente no Estado de São Paulo, há, aproximadamente, quatro milhões de hectares com pastagens de capim-braquiária degradadas, que precisam ser recuperados e sobre os quais podem ser implantadas culturas agrícolas anuais com alta produtividade, como a do, o milho (PORTAS, 2001).

'Departamento de Recursos Naturais, Ciência do Solo, Faculdade de Ciências Agronômicas, Universidade Estadual Paulista, CP 237, 18610-907, Botucatu, SP, Brasil. E-mail: legodoy@fca.unesp.br. *Autor para correspondência. 
Para o cultivo de milho sobre a palhada remanescente da pastagem, é esperada uma baixa resposta à aplicação de $\mathrm{N}$, por isso, no Estado de São Paulo, são recomendados apenas $40 \mathrm{~kg} \mathrm{ha}^{-1}$ de $\mathrm{N}$ em cobertura para produtividade de grãos de 6 a $8 \mathrm{t} \mathrm{ha}^{-1}$ (RAIJ \& CANTARELLA, 1996). No entanto, nessas recomendações, não é considerada a condição que se encontra a pastagem, que pode determinar a quantidade variável de fitomassa deixada sob o solo. FEIGL et al. (1998) citam valores de fitomassa seca da parte aérea de pastagens variando entre $10 \mathrm{a} 15 \mathrm{t} \mathrm{ha}{ }^{-1}$ e radicular entre 15 e 32t ha ${ }^{-1}$. Outro fator que influencia a resposta à adubação nitrogenada de uma cultura sobre a palhada remanescente da pastagem é a espécie da gramínea, pois esta exerce um papel fundamental na disponibilidade de nitrogênio (RIZZARDI, 1998). Em sistemas de produção que envolvem gramíneas com alta relação $\mathrm{C} / \mathrm{N}$ (como a braquiária), antecedendo o cultivo do milho, pode haver a imobilização microbiana de parte do $\mathrm{N}$ aplicado, o que pode reduzir a eficiência da adubação nitrogenada (SCHERER, 2001).

Um dos métodos sugeridos para reduzir a imobilização microbiana é aumentar a dose de $\mathrm{N}$ a ser aplicada na semeadura para $30 \mathrm{~kg} \mathrm{ha}^{-1}$, para que haja $\mathrm{N}$ disponível para o milho na fase inicial (SÁ, 1996). No entanto, como esta imobilização do $\mathrm{N}$ pode variar com a quantidade de resíduos, a relação $\mathrm{C} / \mathrm{N}$, a população microbiana, as condições climáticas e com uma série de fatores, é necessário um indicativo para manejar adequadamente a adubação nitrogenada em cobertura. Uma das alternativas para avaliar a disponibilidade de nitrogênio no solo é através da resposta da planta. Todavia, somente é possível diagnosticar visualmente a deficiência de $\mathrm{N}$ na planta quando esta ocorre de forma aguda; isto é, quando, provavelmente, parte significativa da produção já estiver comprometida (FONTES, 2001).

A clorofila é um pigmento que reflete a cor verde nas plantas e está diretamente associado com o potencial da atividade fotossintética, assim como o estado nutricional das plantas, geralmente, está associado com a quantidade e qualidade de clorofila (ZOTARELLI et al., 2003). A utilização do clorofilômetro portátil SPAD-502 pode predizer, precocemente, a deficiência de $\mathrm{N}$ na planta de milho, através da avaliação da intensidade da cor verde da folha, medida pela absorbância de luz a 650nm pela clorofila da folha, de modo preciso, rápido e não-destrutivo no campo de produção (CHAPMAN \& BARRETO, 1997).

O presente trabalho objetivou avaliar a utilização da intensidade da cor verde da folha, medida pelo clorofilômetro, como indicativo para o manejo da adubação nitrogenada em cobertura, na cultura do milho sob palhada remanescente de braquiária.

\section{MATERIAL E MÉTODOS}

O experimento foi realizado em condições de túnel plástico (tipo arco, com 20m de comprimento, $7 \mathrm{~m}$ de largura e 2,5m de altura), localizado na Faculdade de Ciências Agronômicas, UNESP, Botucatu, SP (2251'51's, 48²6'48' W; altitude de $786 \mathrm{~m}$ ), durante o ano de 2002/2003. Utilizou-se no ensaio vasos de cimento amianto com capacidade de 35 litros ( 37 x $37 \mathrm{~cm}$ de área e 25,5cm de profundidade) e preenchidos com 29 litros de solo classificado como LATOSSOLO VERMELHO distrófico de acordo com EMBRAPA (1999), coletado na camada arável $(0-20 \mathrm{~cm}$ de profundidade), em uma área de pastagem de braquiária (Brachiaria decumbens Stapf.). As características químicas e granulométricas do solo foram determinadas antes da instalação do ensaio, apresentando os seguintes valores: $\mathrm{pH}\left(\mathrm{CaCl}_{2}\right)$ de 4,9; M.O. de $13 \mathrm{~g} \mathrm{dm}^{-3}$; $\mathrm{P}_{\text {(resina) }}$ de $2 \mathrm{mg} \mathrm{dm}^{-3} ; 0,3 ; 12 ; 5 ; 29 \mathrm{mmol}_{\mathrm{c}} \mathrm{dm}^{-3}$, respectivamente, de $\mathrm{K}, \mathrm{Ca}, \mathrm{Mg}, \mathrm{H}+\mathrm{Al} ; 38 \%$ de saturação por bases; 751; 176; $73 \mathrm{~g} \mathrm{~kg}^{-1}$ de areia, silte e argila, respectivamente.

A fitomassa seca de $\boldsymbol{B}$. decumbens, na área em que foi coletado o solo, foi avaliada coletando o material vegetal sobre a superfície do solo e as raízes, a uma profundidade de $0,2 \mathrm{~m}$, em três pontos de amostragem de $0,25 \mathrm{~m}^{2}$, obtendo-se a fitomassa seca de parte aérea e de raízes de 15 e 5 t ha $^{-1}$, respectivamente.

O delineamento experimental foi o de blocos casualizados, seguindo o esquema fatorial $4 \times 4$, com cinco repetições, constituído por quatro níveis de nitrogênio $\left(0,50,100\right.$ e $150 \mathrm{mg} \mathrm{dm}^{-3}$ de solo) e quatro de fitomassa seca da parte aérea de $\boldsymbol{B}$. decumbens $(0,5,10$ e $15 t \mathrm{ha}^{-1}$ ), aplicados em cobertura. A palhada de $\boldsymbol{B}$. decumbens foi coletada em área de pastagem que se encontrava no estádio de florescimento e sem ser pastejada, e apresentou uma relação carbono/ nitrogênio de 50:1. Depois de secada em estufa a $60^{\circ} \mathrm{C}$, durante 72 horas, a palha foi cortada em fragmentos, com aproximadamente $2 \mathrm{~cm}$ de comprimento, e aplicada na quantidade equivalente a $0,5,10$ e $15 \mathrm{tha}^{-1}(0 ; 68,5$; 136,9 e $205,4 \mathrm{~g}$ de fitomassa seca por unidade experimental, respectivamente).

O solo foi corrigido previamente com calcário dolomítico com PRNT de 91\%, visando a obter uma saturação por bases de $70 \%$. Por ocasião da semeadura, foi efetuada aplicação de $\mathrm{P}$ e K nas doses de 150 e $120 \mathrm{mg} \mathrm{dm}^{-3}$ de solo, respectivamente, incorporados ao solo, e de Zn e B nas doses de 1,5 e 
$0,5 \mathrm{mg} \mathrm{dm}{ }^{-3}$, respectivamente, na forma de solução, aplicada na superfície do solo.

$\mathrm{O} \mathrm{N}$ foi aplicado na forma de uréia, sobre a superfície do solo, nas doses equivalentes a 0, 50, 100 e 150mg dm ${ }^{-3}$ de solo (0; 3,22; 6,44 e 9,66 g de uréia por unidade experimental, respectivamente), parceladas em três aplicações: na semeadura do milho, nos estádios de quatro a cinco e de sete a oito folhas expandidas.

Utilizou-se três plantas de milho por vaso do híbrido semi-precoce “Cargill C 333B”, semeado no dia 12 de dezembro de 2002, cultivando-se durante 66 dias. Água foi adicionada ao solo, atingindo $70 \%$ da capacidade máxima de retenção de umidade, sendo o volume necessário determinado por pesagens de quatro unidades experimentais a cada dois dias.

As determinações da intensidade de cor verde da folha (ICV) foram efetuadas nos estádios de quatro a cinco e de sete a oito folhas recentemente expandidas, um dia antes e uma semana após a adubação nitrogenada, sempre no período da manhã, entre nove e dez horas, sombreando o aparelho com o corpo para evitar interferência da luz solar. A ICV foi realizada com o clorofilômetro Minolta SPAD-502, na folha recentemente expandida de todas as plantas da unidade experimental, em dois pontos situados de 15 a $20 \mathrm{~cm}$ da ponta da folha e fixados pelo regulador de profundidade do aparelho em $6 \mathrm{~mm}$ da margem da folha.

A fitomassa seca foi determinada aos 66 dias após a emergência das plantas de milho, coletando-se a parte aérea de duas plantas por parcela, cujo material coletado foi secado em estufa a $60^{\circ} \mathrm{C}$, até peso constante.

Os resultados foram submetidos à análise de variância, de acordo com o teste $\mathrm{F}$, e à análise de regressão, utilizando-se o programa Sisvar v. 4.2. (FERREIRA, 2003). Adotou-se, para expressar a tendência da característica, o modelo que apresentou significância a 5\% de probabilidade e o maior coeficiente de correlação para os resultados obtidos.

\section{RESULTADOS E DISCUSSÃO}

A intensidade de coloração verde da folha (ICV), medida pelo clorofilômetro, foi influenciada pelas doses de $\mathrm{N}$ aplicadas ao solo, nas quatro fases avaliadas (Figura 1). Os níveis de palhada somente tiveram influência significativa sobre a ICV da folha na avaliação aos 36 dias após a emergência - DAE (7 a 8 folhas) (Figura 2B), enquanto que a interação níveis de palhada e doses de nitrogênio foi significativa apenas na avaliação aos 42 DAE (8 a 9 folhas) (Figura 1D). NUNES et al. (2003), ao avaliarem o efeito da palhada de sorgo na cultura do milho, em condições semelhantes, não observaram influência significativa sobre a ICV da folha medida pelo clorofilômetro.

A resposta da planta ao nitrogênio quanto à ICV da folha, já na fase de quatro a cinco folhas (Figura 1A), pode ser explicada, em parte, pelo solo arenoso (75\% de areia), com baixa CTC $\left(46 \mathrm{mmol}_{\mathrm{c}} \mathrm{dm}^{-3}\right)$ e baixo teor de matéria orgânica $\left(13 \mathrm{~g} \mathrm{dm} \mathrm{dm}^{-3}\right)$, o que favorece a resposta do $\mathrm{N}$ aplicado na semeadura. Alguns pesquisadores, como WASKOM et al. (1996) e GODOY et al. (2003), não encontraram diferenças na ICV da folha do milho até o estádio de cinco ou seis folhas, devido à maior disponibilidade de $\mathrm{N}$ do solo, suficiente para atender à pequena demanda em N pela planta de milho até este estádio (BÜLL, 1993). De acordo com SÁ (1996), a aplicação da dose de N de $30 \mathrm{~kg} \mathrm{ha}^{-1}$, na semeadura, proporcionou plantas com coloração de verde intenso e melhor "arranque" do milho que a dose de $\mathrm{N}$ de $120 \mathrm{~kg} \mathrm{ha}^{-1}$ em cobertura, reduzindo ou eliminando a carência inicial de $\mathrm{N}$ devido ao processo de imobilização causado pela decomposição de resíduos da aveia-preta. Esse fato é importante porque demonstra que o clorofilômetro pode indicar diferenças na disponibilidade de $\mathrm{N}$ no solo (imobilizado ou não) pela resposta da planta, a partir do estádio de quatro folhas, fase de definição do potencial produtivo do milho (FANCELLI \& DOURADO NETO, 2000).

Na fase de 4 a 5 folhas, a máxima ICV da folha foi atingida na dose de $\mathrm{N}$ de $37 \mathrm{mg} \mathrm{dm}^{-3}$ (Figura 1A). Para efeito de comparação com as doses utilizadas em campo, a dose de $37 \mathrm{mg} \mathrm{dm}^{-3}$ de $\mathrm{N}$ corresponde a 0,36g planta ${ }^{-1}$, sendo que RAIJ et al. (1996) recomendam de 0,32 a $0,48 g$ planta $^{-1}\left(20\right.$ a $30 \mathrm{~kg} \mathrm{ha}^{-1}$ de $\mathrm{N}$ na semeadura para uma população de 55.555 a 62.500 plantas por hectare) e, portanto, a dose encontrada está dentro da faixa recomendada para o Estado de São Paulo.

No estádio de três a quatro folhas, ARGENTA et al. (2001) consideraram como ideal para o milho a ICV de 45,4. No entanto, a partir deste estádio, o crescimento da planta é muito rápido e a demanda por nutrientes é muito alta. Logo, a ICV nesta fase pode ser alterada após uma semana, sendo sua avaliação pouco válida se não for monitorada periodicamente (semanalmente). Isto pôde ser verificado no presente experimento, no qual a ICV nas plantas que não receberam a adubação em cobertura apresentaram uma redução de 6,7 unidades SPAD (20\%) no valor obtido uma semana antes (Figura 2A) e as plantas que já apresentavam uma ICV de 45,2 unidades SPAD tiveram um aumento de $10 \%$ em resposta à adubação nitrogenada em cobertura (Figura 2A). Assim, PETERSON et al. (1993) preconizam, para o Estado de 


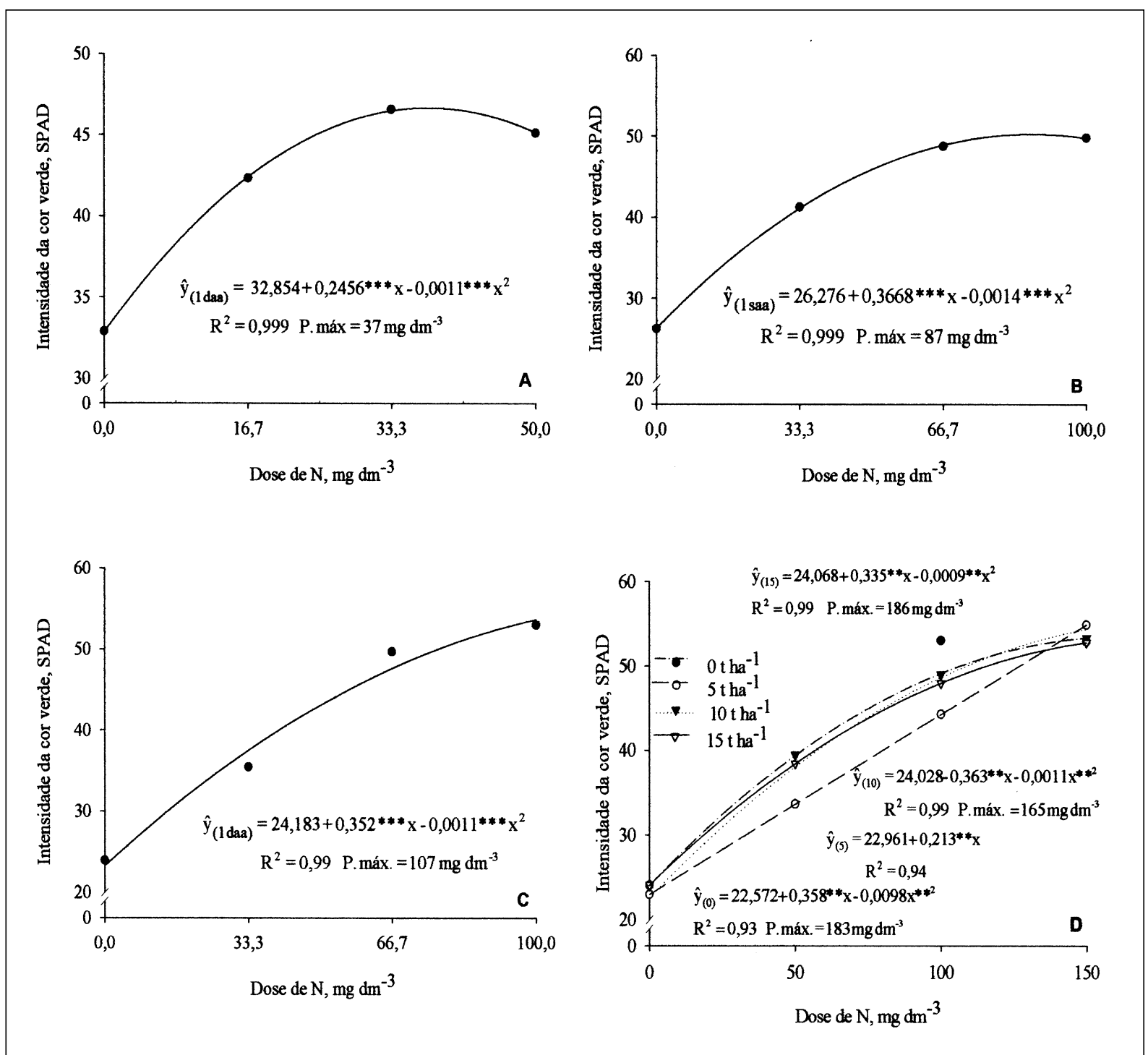

Figura 1 - Intensidade da cor verde da folha, medida pelo clorofilômetro, em função da dose de $\mathrm{N}$ no estádio de 4 a 5 folhas das plantas de milho, um dia antes adubação (daa) nitrogenada de cobertura (A) e uma semana após a adubação (saa) nitrogenada de cobertura (B); no estádio de 7 a 8 folhas das plantas de milho, um dia antes adubação nitrogenada de cobertura (C) uma semana após a adubação nitrogenada de cobertura e em função da quantidade de palha (D).

Nebraska, EUA, a aplicação da primeira parcela da adubação nitrogenada (no estádio de quatro folhas), independentemente da ICV, recomendando a utilização do clorofilômetro para auxiliar na recomendação da adubação nitrogenada a partir do estádio de sete a oito folhas.

Pode-se observar que as plantas que receberam $16,7 \mathrm{mg} \mathrm{dm}^{-3}$ de $\mathrm{N}$ na semeadura (tratamento com $50 \mathrm{mg} \mathrm{dm}^{-3}$ no total), apresentaram redução da ICV mesmo após receber mais uma dose de $\mathrm{N}$ de $16,7 \mathrm{mg}$ $\mathrm{dm}^{-3}$ no estádio de quatro a cinco folhas (Figura 2A). Já as plantas que receberam uma dose de $\mathrm{N}$ de $50 \mathrm{mg}$ $\mathrm{dm}^{-3}$ na semeadura e outra equivalente no estádio de quatro folhas apresentaram um aumento de $10 \%$ no valor da ICV após a adubação. Essas plantas acumularam o dobro da fitomassa seca aos 66 DAE, em relação às plantas adubadas com $33,3 \mathrm{mg} \mathrm{dm}^{-3}$ até o estádio de quatro folhas (Figura 2D). Apesar de a ICV das plantas no estádio de quatro a cinco folhas não servir como um indicativo da necessidade da adubação nitrogenada nesta fase, o acompanhamento da ICV, antes e após a adubação, pode auxiliar na avaliação da adubação nitrogenada realizada e na calibração da próxima aplicação.

No estádio de sete a oito folhas, um dia antes de receber a segunda parcela de adubação, a ICV da 


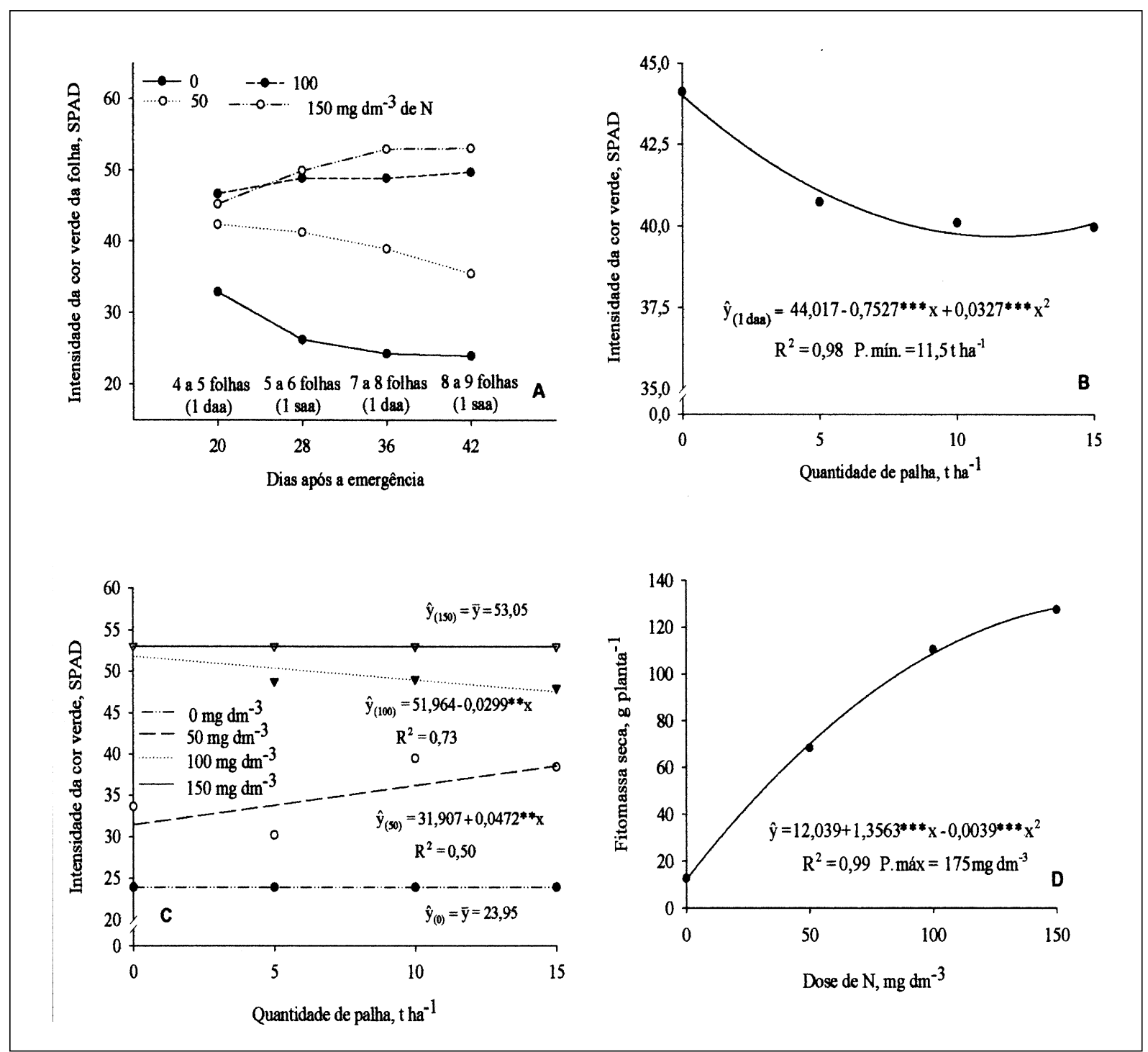

Figura 2 - Intensidade da cor verde da folha, medida pelo clorofilômetro, em função das doses de N no decorrer do período de 28 a 49 dias após a emergência (A); em função da quantidade de palhada remanescente de $\boldsymbol{B}$. decumbens na superfície do solo no estádio de 7 a 8 folhas das (B) e no estádio de 8 a 9 folhas plantas de milho (C). Fitomassa seca acumulada na parte aérea da planta de milho, em função da dose de N, aos 66 dias após a emergência (D).

folha foi influenciada e se ajustou bem às doses de $\mathrm{N}$ aplicadas na primeira parcela da adubação (Figura 1C). A ICV da folha (52,92 unidades SPAD) encontrada na maior dose de $\mathrm{N}\left(100 \mathrm{mg} \mathrm{dm}^{-3}\right)$ foi semelhante à considerada ideal por ARGENTA et al. (2001) para o estádio de seis a sete folhas e também à indicada para atingir-se 95\% da máxima produtividade no experimento de SAINZ ROZAS \& ECHÉVERRIA (1998).

Com sete a oito folhas, antes da adubação, aparece o efeito da palha sobre a ICV, havendo um decréscimo deste com a presença da palha, independentemente da dose de $\mathrm{N}$ adicionada (Figura 2B), tendo o mínimo valor da ICV atingido com a quantidade de palha estimada em $11,5 \mathrm{tha}^{-1}$. Com o aumento da demanda por $\mathrm{N}$ pela planta nesta fase e uma possível imobilização de parte do $\mathrm{N}$ do solo por microorganismos, a redução na quantidade de palhada proporcionou plantas com uma maior ICV da folha, devido à maior disponibilidade de N (BÜLL, 1993).

Uma semana após a segunda adubação em cobertura, no estádio de oito a nove folhas, houve uma interação significativa dos níveis de palha com as dose de $\mathrm{N}$. As plantas não adubadas com $\mathrm{N}$ em cobertura e as que receberam a dose de $\mathrm{N}$ de $150 \mathrm{mg}$ $\mathrm{dm}^{-3}$ não apresentaram alteração na ICV com os níveis de palha de $\boldsymbol{B}$. decumbens (Figura 2C). Com a dose de $\mathrm{N}$ de $50 \mathrm{mg} \mathrm{dm}^{-3}$ no estádio de sete a oito folhas da planta, há uma tendência de aumento da ICV, de 33,6 a 
38,5 unidades SPAD, com o aumento da quantidade de palha de 0 para $15 \mathrm{t} \mathrm{ha}^{-1}$, respectivamente. Este aumento do ICV pode ser devido à mineralização do nitrogênio orgânico do solo e não devido à mineralização do nitrogênio imobilizado na biomassa microbiana, como observado por VARGAS et al. (2005) em experimento com aplicação de $\mathrm{N}$ durante o ciclo do milho em sucessão a aveia preta (relação C:N de 60).

As plantas adubadas com a dose de $\mathrm{N}$ de $100 \mathrm{mg} \mathrm{dm}^{-3}$, ao contrário das adubadas com a dose de $50 \mathrm{mg} \mathrm{dm}^{-3}$, apresentaram uma redução na ICV das folhas com o aumento da quantidade de palha (Figura 2B), semelhante ao observado nas plantas de todos os tratamentos no estádio de sete a oito folhas antes da adubação.

A máxima fitomassa seca acumulada pela parte aérea do milho até os 66 DAE foi estimada na dose de $\mathrm{N}$ de $175 \mathrm{mg} \mathrm{dm}^{-3}$, acima da maior dose utilizada (Figura 2D). O mesmo foi observado para a máxima ICV da folha, aos 44 DAE (Figura 1D), ou seja, as doses utilizadas não permitiram atingir-se um valor máximo de fitomassa seca acumulada e nem da ICV. A dose de $\mathrm{N}$ em cobertura para se obter o máximo acúmulo de fitomassa seca na parte aérea do milho equivale, em média, a $78 \mathrm{~kg} \mathrm{ha}^{-1}$ de $\mathrm{N}$, valor abaixo do citado $(120 \mathrm{~kg}$ ha $^{-1}$ de N) por AMADO et al. (2002) para o cultivo de milho após gramínea de alta quantidade de biomassa produzida $\left(>4 \mathrm{tha}^{-1}\right)$, para produtividade de grãos de 6 a 9 tha $^{-1}$.

Avaliando a tendência da ICV da folha com o decorrer do ciclo da cultura do milho, independentemente da quantidade de palha, pode-se observar que a ausência da aplicação de N e a aplicação de $50 \mathrm{mg} \mathrm{dm}^{-3}$ de $\mathrm{N}$ não permitiram manter a ICV, medida no estádio de quatro folhas, havendo uma redução até o estádio de oito folhas (Figura 2A). Doses de N maiores que $100 \mathrm{mg} \mathrm{dm}^{-3}$ permitiram manter-se ou até elevar-se a ICV das plantas, do estádio de quatro até o estádio de oito a nove folhas. A manutenção de valores mais altos de ICV da folha tem-se refletido em maiores produtividades na cultura do milho, como observado por WASKOM et al. (1996); GODOY et al. (2003).

\section{CONCLUSÕES}

O monitoramento da intensidade de cor verde (ICV) da folha, um dia antes e uma semana após a adubação, pode auxiliar na avaliação da disponibilidade de $\mathrm{N}$ para o milho durante o ciclo. As quantidades de palhada de braquiária influenciaram a ICV da folha somente no estádio de sete a oito folhas. A manutenção de maiores ICVs da folha do estádio de 4-5 (46,6 unidades SPAD) até o estádio de 8-9 folhas
(53,0 unidades SPAD) possibilitou o maior acúmulo da fitomassa seca na parte aérea do milho.

\section{AGRADECIMENTOS}

Ao Conselho Nacional de Desenvolvimento Científico e Tecnológico (CNPq), pela concessão da bolsa para obtenção do título de mestre do segundo autor.

\section{REFERÊNCIAS}

AMADO, T.J.C. et al. Recomendação de adubação nitrogenada para o milho no RS e SC adaptada ao uso de culturas de cobertura do solo, sob sistema de plantio direto. Revista Brasileira de Ciência do Solo, Viçosa, v.26, n.2, p.241-248, 2002.

ARGENTA, G. Monitoramento do nível de nitrogênio na planta como indicador da adubação nitrogenada em milho. 2001. 112f. Tese (Doutorado em Fitotecnia) - Programa de Pós-graduação em Fitotecnia, Faculdade de Agronomia, Universidade Federal do Rio Grande do Sul, Porto Alegre.

BÜLL, L.T. Nutrição mineral do milho. In: BÜLL, L.T.; CANTARELLA, H. (Eds). Cultura do milho: fatores que afetam a produtividade. Piracicaba: POTAFOS, 1993. p.67145

CHAPMAN, S.C.; BARRETO, H.J. Using a chlorophyll meter to estimate specific leaf nitrogen of tropical maize during vegetative growth. Agronomy Journal, Madison, v.89, n.4, p.557-562, 1997.

EMBRAPA. Centro Nacional de Pesquisa de Solos. Sistema Brasileiro de Classificação de Solos. Rio de Janeiro: Embrapa Solos, 1999. 412p.

FANCElli, A.L.; DOURAdo Neto, D. Produção de milho. Guaíba: Agropecuária, 2000. 360p.

FEIGL, B.J.et al. Balanço de carbono e biomassa microbiana em solos da Amazônia. In: MELO, I.S.; AZEVEDO, J.L. (Eds). Ecologia microbiana. Jaguariúna: Embrapa-CNPA, 1998. p.423-441.

FERREIRA, D.F. Sisvar versão 4.2. Lavras: DEX/UFLA, 2003. 79p.

FONTES, P.C.R. Diagnóstico do estado nutricional das plantas. Viçosa: UFV, 2001. 122p.

GODOY, L.J.G. et al. Adubação nitrogenada na cultura do milho baseada na medida do clorofilômetro e no índice de suficiência em nitrogênio (ISN). Acta Scientiarum: Agronomy, Maringá, v.25, n.2, p.373-380, 2003.

MEIRELLES, N.M.F. Degradação de pastagens-critério de avaliação. In: PAULINO, V.T.; FERREIRA, L.G. Recuperação de pastagens. 2.ed. Nova Odessa: Instituto de Zootecnia, 1999. p.15-22.

NUNES, J.C.S. et al. Efeito da palhada de sorgo localizada na superfície do solo em características de plantas de soja e de milho. Revista Ceres, Viçosa, v.50, n. 287, p.115-126, 2003.

PETERSON, T.A. et al. Using a chlorophyll meter to improve $\mathbf{N}$ management. Lincoln: University of Nebraska, 
Cooperative Extension, Institute of Agricultural and Natural Resources, 1993. 5p.

PORTAS, A.A. Integração agricultura-pecuária. Campinas. CATI, 2001. 4p. (CATI responde, 44).

RAIJ, B.; CANTARELLA, H. Milho para grãos e silagem. In: INSTITUTO AGRONÔMICO/FUNDAG. Recomendações de adubação e calagem para o Estado de São Paulo. Campinas: IAC/FUNDAG, 1996. p.56-59. (Boletim Técnico, 100).

RIZZARDI, M.A. Manejo do nitrogênio em sistemas de rotação de culturas. In: REUNIÃO CENTRO-SUL DE ADUBAÇÃO VERDE E ROTAÇÃO DE CULTURAS, 5., 1995, Chapecó, SC. Resumos... Florianópolis: Epagri, 1998. p.160.

SÁ, J.C.M. Manejo do nitrogênio na cultura do milho no sistema de plantio direto. Passo Fundo: Aldeia Norte, 1996. $24 \mathrm{p}$.

SAINZ ROZAS, H.; ECHEVERRÍA, H.E. Relacíon entre las lecturas del medidor de clorofila (Minolta SPAD 502) en distintos estadios del ciclo del cultivo de maiz y el rendimiento en grano.
Revista da Facultad de Agronomía, Buenos Aires, v.103, n.1, p.37-44, 1998.

SCHERER, E.E. Avaliação de fontes e épocas de aplicação de adubo nitrogenado na cultura do milho no sistema de plantio direto. Agropecuária Catarinense, Florianópolis, v.14, n.1, p.48-53, 2001.

VARGAS, L.K. et al. Imobilização de nitrogênio em solo cultivado com milho em sucessão à aveia preta nos sistemas de plantio direto e convencional. Ciência Rural, v.35, n.1, p.76-83, 2005.

WASKOM, R.M. et al. Monitoring nitrogen status of corn with a portable chlorophyll meter. Communications in Soil Science and Plant Analysis, New York, v.27, p.554-560, 1996.

ZOTARELLI, L. et al. Calibração do medidor de clorofila Minolta SPAD-502 para avaliação do conteúdo de nitrogênio do milho. Pesquisa Agropecuária Brasileira, Brasília, v.38, n.9, p.1117-1122. 2003 